\title{
Changes in Markers of Mineral and Bone Disorders and Mortality in Incident Hemodialysis Patients
}

\author{
Melissa Soohoo ${ }^{a}$ Mingliang Feng ${ }^{a, f}$ Yoshitsugu Obi ${ }^{a} \quad E^{a}$ i Streja ${ }^{a}$ \\ Connie M. Rhee ${ }^{a, b}$ Wei Ling Lau ${ }^{b}$ Jialin Wanga, Vanessa A. Ravel $^{a}$ \\ Steven Brunelli ${ }^{\mathrm{e}}$ Csaba P. Kovesdy ${ }^{d}$ Kamyar Kalantar-Zadeh ${ }^{\mathrm{a}-\mathrm{c}}$ \\ ${ }^{a}$ Harold Simmons Center for Kidney Disease Research and Epidemiology and ${ }^{\mathrm{b}}$ Division of Nephrology and \\ Hypertension, University of California Irvine, School of Medicine, Orange, Calif., ' Department of Epidemiology, UCLA \\ Fielding School of Public Health, Los Angeles, Calif., 'Division of Nephrology, University of Tennessee Health Science \\ Center, Memphis, Tenn., and e DaVita Clinical Research, Minneapolis, Minn., USA; ${ }^{f}$ Division of Nephrology, Jiangmen \\ Central Hospital, Guangdong, and ${ }^{9}$ Division of Nephrology, Tianjin Union Medical Center, Tianjin, China
}

\section{Key Words}

Epidemiology · Disorders of calcium/phosphate metabolism - Parathyroid hormone - Alkaline phosphatase . Nutrition $\cdot$ Statistical methods

\section{Abstract \\ Background: Abnormalities in mineral and bone disorder (MBD) markers are common in patients with chronic kidney disease. However, previous studies have not accounted for their changes over time, and it is unclear whether these changes are associated with survival. Methods: We exam- ined the association of change in MBD markers (serum phos- phorus (Phos), albumin-corrected calcium $\left(\mathrm{Ca}_{\mathrm{Alb}}\right)$, intact parathyroid hormone (iPTH) and alkaline phosphatase (ALP)) during the first 6 months of hemodialysis (HD) with all-cause mortality across baseline MBD strata using survival models adjusted for clinical characteristics and laboratory measure- ments in 102,754 incident HD patients treated in a large di- alysis organization between 2007 and 2011. Results: Across all MBD markers (Phos, $\mathrm{Ca}_{\mathrm{Alb}}$, iPTH and ALP), among patients whose baseline MBD levels were higher than the reference range, increase in MBD levels was associated with higher}

mortality (reference group: MBD level within reference range at baseline and no change at 6 months follow-up). Conversely, decrease in Phos and iPTH, among baseline Phos and PPTH levels lower than the reference range, respectively, were associated with higher mortality. An increase in ALP was associated with higher mortality across baseline strata of ALP $\geq 80$ $\mathrm{U} / \mathrm{I}$. However, patients with baseline ALP $<80 \mathrm{U} / \mathrm{I}$ trended towards a lower risk of mortality irrespective of the direction of change at 6 months follow-up. Conclusions: There is a differential association between changes in MBD markers with mortality across varying baseline levels in HD patients. Further study is needed to determine if consideration of both baseline and longitudinal changes in the management of MBD derangements improves outcomes in this population.

(c) 2016 S. Karger AG, Basel

\section{Introduction}

High serum concentrations of phosphorus (Phos), calcium, intact parathyroid hormone (iPTH) and alkaline phosphatase (ALP) are frequently found in patients with advanced chronic kidney disease (CKD) and are associ-

\section{KARGER}

E-Mail karger@karger.com www.karger.com/ajn (c) 2016 S. Karger AG, Basel

0250-8095/16/0432-0085\$39.50/0
Kamyar Kalantar-Zadeh, MD, MPH, PhD

Harold Simmons Center for Kidney Disease Research and Epidemiology, Division of Nephrology and Hypertension, University of California Irvine, School of Medicine 101 The City Drive South, City Tower, Suite 400 - ZOT: 4088

Orange, CA 92868-3217 (USA), E-Mail kkz@ uci.edu 


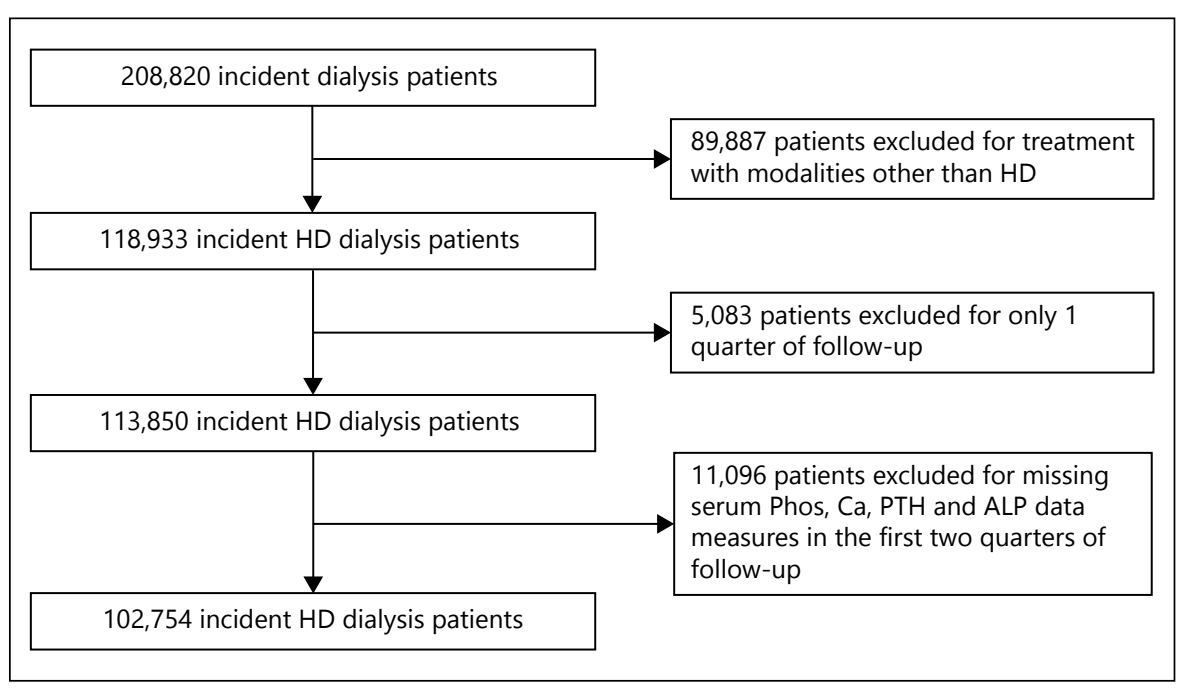

Fig. 1. Cohort construction.

ated with increased cardiovascular disease and mortality, especially in those with end-stage renal disease (ESRD) [1-9]. In addition, changes in these minerals may result in CKD-mineral and bone disease (CKD-MBD), leading to structural and functional abnormalities in the bone and cardiovascular system, as well as higher morbidity and mortality in ESRD patients [10].

Although clinical practice guidelines recommend that the therapeutic management of CKD-MBD should be based on the trends of these MBD markers instead of a singular laboratory result [11-13], few studies have evaluated the association between changes in MBD markers over time with outcomes, or how baseline levels modify these relationships $[9,14]$. Furthermore, previous studies have examined study populations with heterogeneous dialysis vintage. Mortality is highest during the early period after hemodialysis (HD) initiation $[14,15]$, and thus the association of these changes with all-cause mortality may differ in long-term HD patients. Therefore, we sought to examine the association between changes in serum concentrations of albumin-corrected calcium $\left(\mathrm{Ca}_{\mathrm{Alb}}\right)$, Phos, iPTH and ALP in the first 6 months after initiation of dialysis with all-cause mortality across varying baseline concentrations of these MBD markers in a large contemporary cohort of incident HD patients.

\section{Methods}

Study Population and Data Source

We examined data from patients who initiated treatment within a large dialysis organization (LDO) in the US between 2007 and 2011, with follow-up concluding on December 31, 2011 [16]. This study was approved by the Institutional Review Committees of Los Angeles Biomedical Research Institute at Harbor-UCLA, University of California, Irvine, and the DaVita Clinical Research. The need for written consent was waived due to the study's large sample size, patient anonymity and non-intrusive nature.

Patients treated for at least 60 consecutive days were considered to be on maintenance HD. Patient follow-up was divided into consecutive patient quarters, representing 91-day intervals from the start of dialysis treatment. The baseline quarter (Q1) for each patient was defined as the first 91-day interval in which the patient was treated with HD. Patients were censored at the time of renal transplantation, transfer to a different LDO facility or at the end of the study period. Patients were excluded from this study if they were treated with modalities other than in-center HD, were treated for less than 91 days (only had 1 quarter of follow-up) or had missing data for Phos, $\mathrm{Ca}_{\mathrm{Alb}}$, $\mathrm{iPTH}$ and ALP measurements at baseline and the following quarter.

\section{Demographic and Clinical Measures}

The final study population was composed of 102,754 incident HD patients (fig. 1). Data obtained on mortality and baseline demographics, including self-categorized race/ethnicity and primary insurance were acquired from the LDO's electronic records database. Intravenous medications were also obtained from the LDO's records and calculated as median dose per week.

The following 11 pre-existing comorbidities were obtained from ICD-9 codes from the LDO's electronic records database: (1) diabetes mellitus, (2) hypertension, (3) congestive heart failure, (4) atherosclerotic heart disease, (5) cerebrovascular disease, (6) other cardiovascular disease, (7) chronic obstructive pulmonary disease, (8) history of cancer, (9) HIV, (10) alcohol abuse and (11) substance abuse.

\section{Laboratory Measures}

Blood samples were drawn using standard techniques in all dialysis clinics and were transported to the LDO's central laboratory in Deland, Florida, within $24 \mathrm{~h}$. All laboratory values, including serum measurements of Phos, $\mathrm{Ca}_{\mathrm{Alb}}$, iPTH and ALP, were mea-
86

Am J Nephrol 2016;43:85-96

DOI: $10.1159 / 000444890$
Soohoo et al. 
sured on a monthly basis and by automated and standardized methods. All repeated laboratory measurements were averaged during each 91-day interval to minimize the effects of short-term variability. When serum albumin concentration was $<4.0 \mathrm{~g} / \mathrm{dl}$, we calculated $\mathrm{Ca}_{\mathrm{Alb}}$ as follows: $\mathrm{Ca}_{\mathrm{Alb}}=\operatorname{serum}$ calcium $(\mathrm{mg} / \mathrm{dl})+0.8 \times$ $(4.0$ - serum albumin $(\mathrm{g} / \mathrm{dl}))$ [17]. Delivered dialysis dose was estimated by single-pooled Kt/V using the urea kinetic model.

We chose the first 6-month interval of HD treatment to assess changes in the baseline and follow-up levels of CKD-MBD markers because serum Phos and iPTH concentrations tends to be high prior to the initiation of maintenance dialysis treatment and then gradually decreases and stabilizes usually within the first 6 months of treatment. Changes in MBD markers were calculated by subtracting the mean concentrations during the first quarter (Q1) from the mean concentrations during the second quarter (Q2).

We divided each baseline concentration of Phos, $\mathrm{Ca}_{\mathrm{Alb}}$, iPTH and ALP into 4 groups (Phos $<3.5,3.5-<5.5,5.5-<7.5$ and $\geq 7.5 \mathrm{mg}$ / $\mathrm{dl} ; \mathrm{Ca}_{\mathrm{Alb}}<8.4,8.4-<9.5,9.5-<10.2$ and $\geq 10.2 \mathrm{mg} / \mathrm{dl}$; $\mathrm{iPTH}<150$, $150-<300,300-<600$ and $\geq 600 \mathrm{pg} / \mathrm{ml}$; ALP $<80,80-<120,120-$ $<160$ and $\geq 160 \mathrm{U} / \mathrm{l}$, respectively) based on prior studies [9, 18]. Within each baseline category of each CKD marker, we examined the change in marker level from Q1 to Q2 across 3 groups: unchanged, increased and decreased, based on the following intervals per marker: Phos: $\pm 0.5 \mathrm{mg} / \mathrm{dl}, \mathrm{Ca}_{\mathrm{Alb}}: \pm 0.2 \mathrm{mg} / \mathrm{dl}$, iPTH: $\pm 50 \mathrm{pg} / \mathrm{ml}$ and ALP: $\pm 10 \mathrm{U} / \mathrm{l}$. For example, the change in Phos categories were 'unchanged' $( \pm 0.5 \mathrm{mg} / \mathrm{dl})$, 'increased' $(>0.5 \mathrm{mg} / \mathrm{dl})$ and 'decreased' $(<-0.5 \mathrm{mg} / \mathrm{dl})$. These intervals were determined by the distribution of the change between quarters in the cohort. We categorized patients into a total of 12 groups according to baseline level and directionality of change (4-by-3) and examined their associations with all-cause mortality.

\section{Statistical Methods}

Data were summarized using proportions, means \pm SD, medians (interquartile range (IQR)), where appropriate. Tests for trend analyses were used to quantify the relationship among baseline CKD-MBD marker groups.

Cox proportional hazards models were used to determine the relationship between change in blood concentrations of CKDMBD-related parameters (Phos, $\mathrm{Ca}_{\mathrm{Alb}}$, iPTH and ALP) and allcause mortality across baseline strata. Follow-up time started after 91 days from HD initiation. For each analysis, 3 levels of hierarchical adjustments were examined:

(I) Unadjusted models included entry calendar quarter.

(II) Case-mix adjusted models that included all variables included in the unadjusted model plus age, sex, race/ethnicity (White, African American, Hispanic, Asian and other), 11 preexisting comorbidities as well as primary insurance (Medicare, Medicaid and other), vascular access (catheter, arteriovenous fistula or graft), cause of ESRD (diabetes, hypertension, glomerulonephritis, cystic kidney disease, other) and dialysis dose as indicated by single-pool Kt/V (spKt/V). Both baseline and subsequent quarter values of vascular access and $\mathrm{spKt} / \mathrm{V}$ were included in the model.

(III) Models adjusted for case-mix and malnutrition-inflammation complex syndrome (MICS) covariates, which included all of the covariates in the case-mix model as well as the following quarterly averaged variables: body mass index and laboratory surrogates associated with clinical outcomes in HD patients including serum concentrations of (1) albumin, (2) creatinine, (3) total iron binding capacity, (4) ferritin, (5) bicarbonate, (6) peripheral white blood cell count, (7) lymphocyte percentage, (8) hemoglobin, (9) iron saturation, (10) normalized protein catabolic rate. Models were additionally adjusted for Phos, $\mathrm{Ca}_{\mathrm{Alb}}$, iPTH and ALP, unless the particular CKD-MBD marker was the exposure of interest. Finally, the median dose per week of active vitamin D medications administered intravenously was also included. Both baseline and subsequent quarter values were included for all laboratory covariates and medication dosages to account for the change in these variables over time.

For each MBD marker of interest, we examined the effect modification of the association between the change in MBD level with mortality according to baseline MBD level in the fully adjusted case-mix and MICS model. These interaction terms were evaluated by Wald tests simultaneously for each CKDMBD-related parameters.

In each model, the referent group was the second lowest baseline concentration group and exhibited no change in the subsequent quarter (Phos $3.5-<5.5 \mathrm{mg} / \mathrm{dl} ; \mathrm{Ca}_{\mathrm{Alb}} 8.4-<9.5 \mathrm{mg} / \mathrm{dl}$; iPTH $150-<300 \mathrm{pg} / \mathrm{ml} ;$ ALP $80-<120 \mathrm{U} / \mathrm{l})$. In sensitivity analyses, the group exhibiting no change in concentration for each baseline strata was chosen as the referent group in order to compare the association of an excessive change in MBD marker concentration within each baseline strata.

Data was missing on average, $1 \%$ for the cohort. Missing values were handled by multiple imputation. All statistical analyses were carried out with SAS, version 9.4 (SAS Institute, Inc., Cary, N.C., USA).

\section{Results}

The final study population was composed of 102,754 incident HD patients with available measurements of Phos, $\mathrm{Ca}_{\mathrm{Alb}}$, iPTH and ALP during the first 6 months of treatment. Patients had a mean \pm SD age of $63 \pm 15$ years, among whom $44 \%$ were female, $32 \%$ were African American and $60 \%$ were diabetic (table 1). In terms of comorbid conditions, $52 \%$ of patients had hypertension, $39 \%$ had a history of congestive heart failure and $15 \%$ had atherosclerotic heart disease prior to dialysis initiation. Overall follow-up time starting from 91 days after dialysis initiation was median (IQR): 475 (200-889) days.

Baseline serum concentrations of Phos, $\mathrm{Ca}_{\mathrm{Alb}}$, iPTH and ALP were median (IQR) $4.8(4.2-5.6) \mathrm{mg} / \mathrm{dl}, 9.1$ (8.8-9.4) mg/dl, 317 (201-490) pg/ml and 87 (69-114) $\mathrm{U} / \mathrm{l}$, respectively. Median changes in these concentrations from baseline to the subsequent quarter were $0.20(-0.44$ to 0.83$) \mathrm{mg} / \mathrm{dl}, 0.04(-0.20$ to 0.30$) \mathrm{mg} / \mathrm{dl},-59.8(-190.3$ to 29.0$) \mathrm{pg} / \mathrm{ml}$ and 0 (-12.5 to 12.7 ) U/l, respectively.

The association of the change in serum Phos, $\mathrm{Ca}_{\mathrm{Alb}}$, iPTH concentrations with all-cause mortality differed by baseline concentration (p interaction $<0.001$ for each MBD marker). There was also trend towards effect modification 
Table 1. Demographic and clinical characteristics of 102,754 incident HD patient

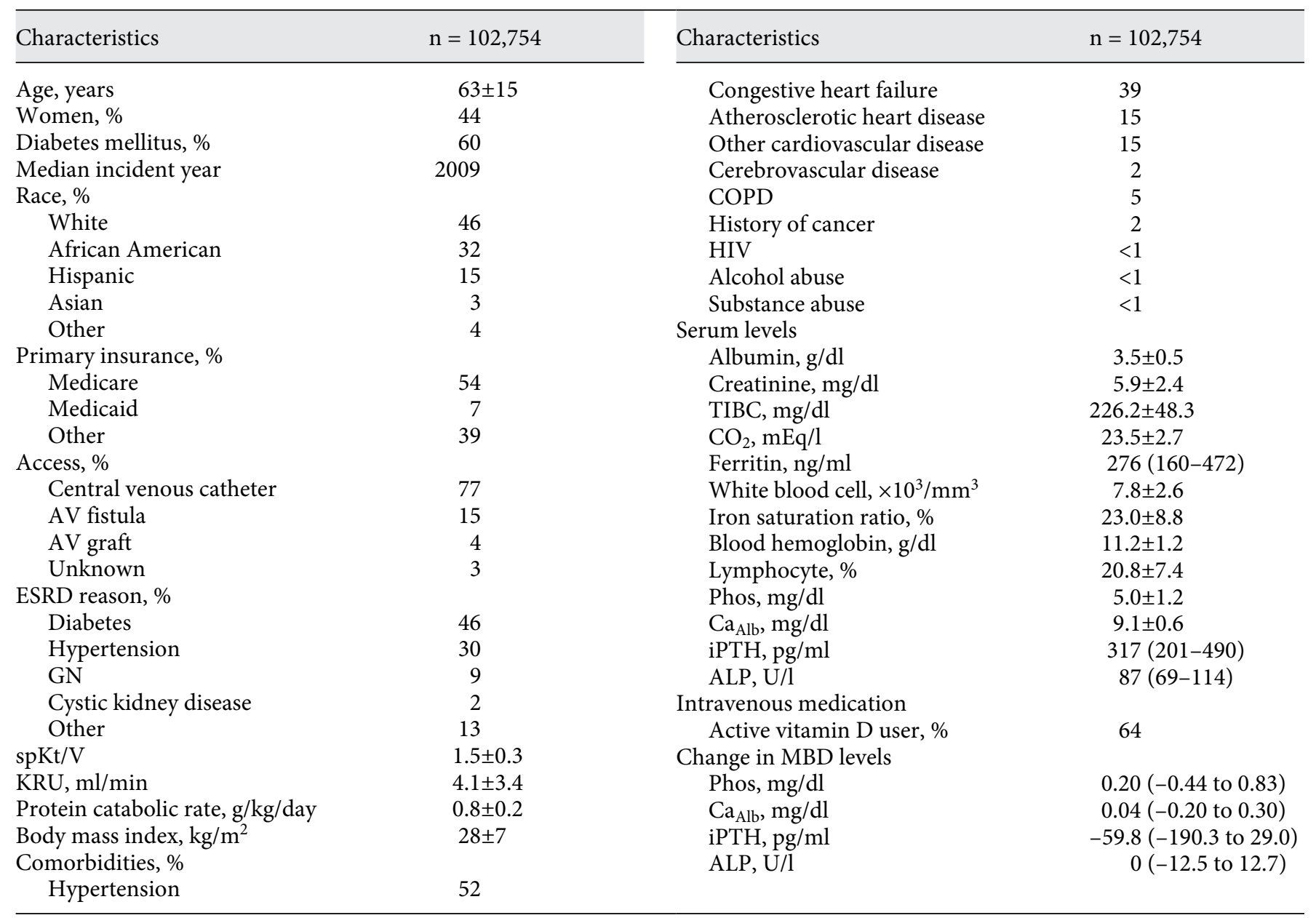

of the association of change in ALP concentrations and mortality according to baseline ALP level $(\mathrm{p}$ interaction = 0.054 ). Therefore, the following survival analyses were conducted after stratifying patients into 12 groups according to 4 baseline groups and 3 levels of change in the subsequent quarter.

\section{Changes in Serum Phosphorous Concentrations and} All-Cause Mortality

The median (IQR) baseline serum Phos concentration was $4.8(4.2-5.6) \mathrm{mg} / \mathrm{dl}$. Patients with higher baseline Phos concentrations were more likely to be younger, male, Hispanic, have a lower residual renal urea clearance (KRU) and have a history of congestive heart failure (online suppl. table 1; for all online suppl. material, see www. karger.com/doi/10.1159/000444890).

Table 2 and figure 2 show the all-cause mortality hazard ratios (HRs) for 3 levels of change from baseline to the next quarter across 4 groups of baseline serum Phos concentrations (reference: baseline serum Phos 3.5 $-<5.5 \mathrm{mg}$ / $\mathrm{dl}$ and unchanged from Q1 to Q2). Among patients whose serum concentrations did not change from baseline to the subsequent quarter of treatment, baseline serum Phos concentrations showed a J-shaped association with mortality, with the highest baseline strata (Phos $\geq 7.5 \mathrm{mg} / \mathrm{dl}$ ) exhibiting the highest mortality risk (aHR 2.01, 95\% CI 1.72-2.36). Relative to the reference group, patients who experienced an increase or decrease in Phos in the subsequent quarter had a higher risk of mortality across all strata of baseline Phos $\geq 3.5 \mathrm{mg} / \mathrm{dl}$.

Adjusted HR for all-cause mortality tended to be highest in patients who experienced a Phos increase $>0.5 \mathrm{mg} /$ $\mathrm{dl}$ in the subsequent quarter, especially among the highest baseline concentrations of Phos (Phos 5.5 $-<7.5$ and $\geq 7.5$ $\mathrm{mg} / \mathrm{dl})$. Similarly, an excessive fall of $<-0.5 \mathrm{mg} / \mathrm{dl}$ from low baseline Phos concentrations of $<3.5 \mathrm{mg} / \mathrm{dl}$ was also 
Table 2. All-cause mortality HRs in baseline serum Phos groups and their changes in 102,754 incident HD patients

\begin{tabular}{|c|c|c|c|c|c|c|c|c|c|}
\hline \multirow{2}{*}{$\begin{array}{l}\text { Baseline } \\
\text { Phos } \\
\text { group, } \\
\text { mg/dl }\end{array}$} & \multirow[t]{2}{*}{$\begin{array}{l}\text { Phos change, } \\
\mathrm{mg} / \mathrm{dl}\end{array}$} & \multirow[t]{2}{*}{$\mathrm{n}$} & \multirow[t]{2}{*}{$\begin{array}{l}\text { Event } \\
\text { rate* }\end{array}$} & \multicolumn{2}{|l|}{ Unadjusted } & \multicolumn{2}{|l|}{ Case-mix adjusted } & \multicolumn{2}{|l|}{$\begin{array}{l}\text { Case-mix and } \\
\text { MICS-adjusted }\end{array}$} \\
\hline & & & & HR (95\% CI) & $\mathrm{p}$ value & HR (95\% CI) & $\mathrm{p}$ value & HR (95\% CI) & $\mathrm{p}$ value \\
\hline \multirow[t]{3}{*}{$<3.5$} & Decreased $(<-0.5)$ & 305 & 607 & $4.01(3.40-4.73)$ & $<0.0001$ & $3.11(2.63-3.67)$ & $<0.0001$ & $1.67(1.41-1.97)$ & $<0.0001$ \\
\hline & Unchanged $( \pm 0.5)$ & 2,583 & 277 & $1.80(1.68-1.94)$ & $<0.0001$ & $149(1.39-1.60)$ & $<0.0001$ & $1.08(1.00-1.16)$ & 0.0486 \\
\hline & Increased $(>0.5)$ & 5,088 & 233 & $1.51(1.43-1.60)$ & $<0.0001$ & $1.31(1.24-1.38)$ & $<0.0001$ & $1.05(0.99-1.11)$ & 0.1061 \\
\hline \multirow{2}{*}{$3.5-<5.5$} & Unchanged $( \pm 0.5)$ & 28,840 & 154 & Ref. & Ref. & Ref. & Ref. & Ref. & Ref. \\
\hline & Increased $(>0.5)$ & 25,675 & 166 & $1.08(1.04-1.11)$ & $<0.0001$ & $1.12(1.08-1.16)$ & $<0.0001$ & $1.14(1.10-1.18)$ & $<0.0001$ \\
\hline \multirow{3}{*}{$5.5-<7.5$} & Decreased $(<-0.5)$ & 10,251 & 143 & $0.92(0.88-0.97)$ & 0.0006 & $1.07(1.02-1.12)$ & 0.000 & $1.22(1.16-1.28)$ & $<0.0001$ \\
\hline & Unchanged $( \pm 0.5)$ & 9,343 & 120 & $0.77(0.74-0.81)$ & $<0.0001$ & $0.98(0.93-1.03)$ & 0.5016 & $1.23(1.17-1.30)$ & $<0.0001$ \\
\hline & Increased $(>0.5)$ & 6,536 & 137 & $0.88(0.84-0.93)$ & $<0.0001$ & $1.21(1.14-1.28)$ & $<0.0001$ & $1.53(1.44-1.62)$ & $<0.0001$ \\
\hline
\end{tabular}

* Per 1,000 patient-years.

Fig. 2. Association of change in serum Phos and all-cause mortality across strata of baseline concentration (case-mix and MICS-adjusted).

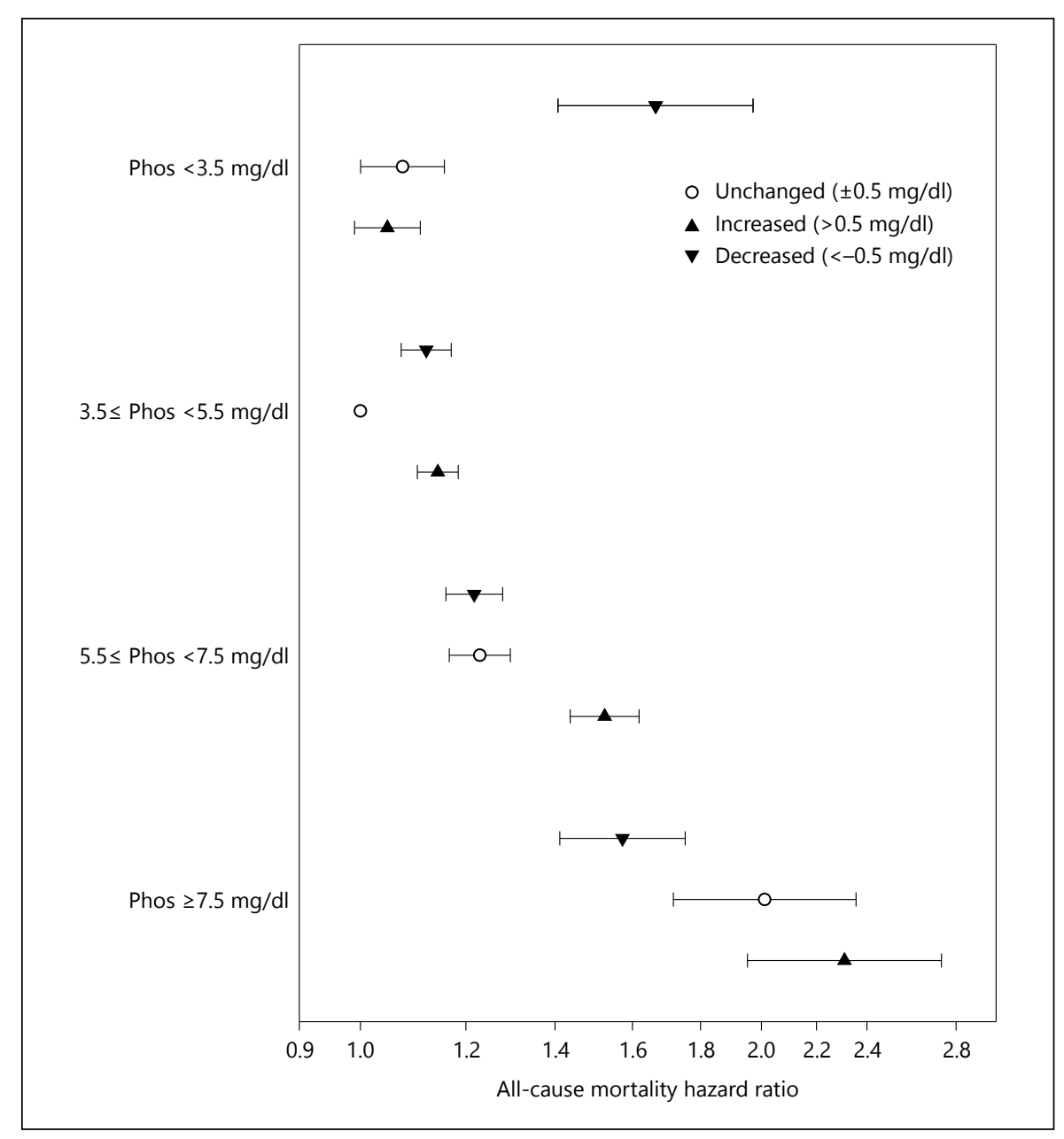


Table 3. All-cause mortality HRs in baseline $\mathrm{Ca}_{\mathrm{Alb}}$ groups and their changes in 102,754 incident $\mathrm{HD}$ patients

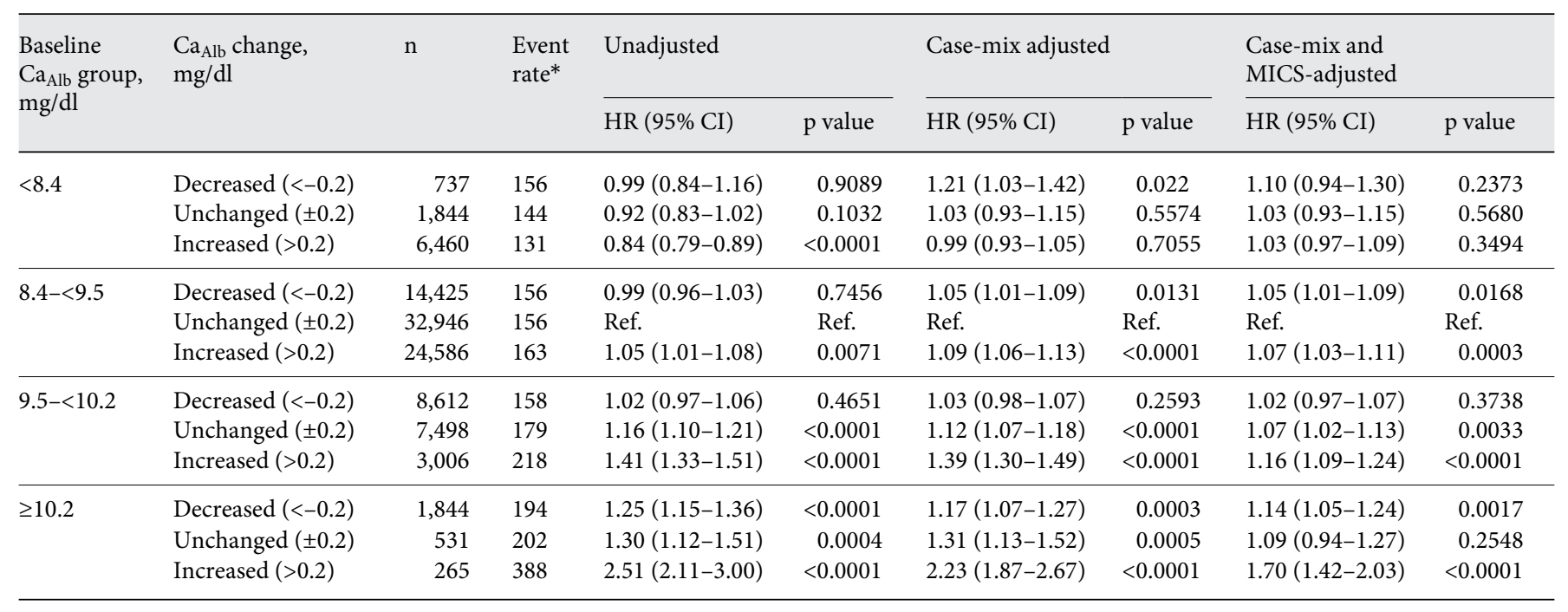

* Per 1,000 patient-years.

associated with higher risk of mortality (aHR 1.67, 95\% CI 1.41-1.97; fig. 2). This was also evident in sensitivity analysis where marker change was evaluated independently in each baseline stratum. An increase in Phos for patients in baseline strata Phos 3.5-<5.5 and 5.5-<7.5 $\mathrm{mg} / \mathrm{dl}$, as well a further decrease from baseline Phos $<3.5$ $\mathrm{mg} / \mathrm{dl}$ exhibited higher mortality in comparison to patients whose Phos measurements baseline were unchanged (online suppl. fig. 1).

\section{Changes in Albumin-Corrected Serum Calcium \\ Concentrations and All-Cause Mortality}

Median (IQR) baseline serum $\mathrm{Ca}_{\mathrm{Alb}}$ concentration was 9.1 (8.8-9.4) mg/dl. Patients with high baseline $\mathrm{Ca}_{\mathrm{Alb}}$ concentrations were more likely to be older, female, African American and hypertensive (online suppl. table 2).

Table 3 shows the all-cause mortality HRs for 3 levels of change from baseline to the subsequent quarter across 4 groups of baseline serum $\mathrm{Ca}_{\mathrm{Alb}}$ concentrations (reference: baseline serum $\mathrm{Ca}_{\mathrm{Alb}} 8.4-<9.5 \mathrm{mg} / \mathrm{dl}$ and unchanged from Q1 to Q2). In unadjusted models, patients in the lowest baseline $\mathrm{Ca}_{\mathrm{Alb}}$ stratum and who had a subsequent increase $\mathrm{Ca}_{\mathrm{Alb}}$ had the lowest mortality risk. However, this association was attenuated after fully adjusting for case-mix and MICS variables. Similar to trends seen with Phos, there was a trend toward higher risk of mortality among patients who experienced an increase in $\mathrm{Ca}_{\mathrm{Alb}}$ in their subsequent quarter across all baseline groups of $\mathrm{Ca}_{\mathrm{Alb}} \geq 8.4 \mathrm{mg} / \mathrm{dl}$ (fig. 3). The highest mortality was seen in patients who experienced a further increase in $\mathrm{Ca}_{\mathrm{Alb}}$ from already high baseline $\mathrm{Ca}_{\mathrm{Alb}}$ concentrations (aHR 1.70, 95\% CI 1.42-2.03). This association was also evident when examining the association of change with respect to baseline strata (online suppl. fig. 2). Finally, patients in baseline strata $\mathrm{Ca}_{\mathrm{Alb}} 8.4-<9.5$ and $\geq 10.2 \mathrm{mg} / \mathrm{dl}$ and who experienced a decrease in $\mathrm{Ca}_{\mathrm{Alb}}$ in the next quarter had a higher risk of mortality compared to the reference group (aHR 1.05, 95\% CI 1.01-1.09, aHR 1.14, 95\% CI 1.05-1.24, respectively; fig. 3).

Change in Serum iPTH Level and All-Cause Mortality Median (IQR) baseline serum iPTH concentrations were 317 (201-490) pg/ml. Patients with high baseline iPTH concentrations were more likely to be younger, African American and hypertensive (online suppl. table 3).

Table 4 shows the all-cause mortality HRs for 3 levels of change from baseline to the next quarter across 4 groups of baseline serum iPTH concentrations (reference: baseline serum iPTH $150-<300 \mathrm{pg} / \mathrm{ml}$ and unchanged from Q1 to Q2). In the unadjusted model, higher baseline iPTH concentrations were associated with better survival, irrespective of the direction of change in the subsequent quarter. However, after further adjustment for laboratory markers this association reversed, especially among patients whose iPTH increased in the next quarter across baseline groups of iPTH $\geq 150 \mathrm{pg} / \mathrm{ml}$. Patients whose lev- 
Table 4. All-cause mortality HRs in baseline serum iPTH groups and their changes 102,754 incident HD patients

\begin{tabular}{|c|c|c|c|c|c|c|c|c|c|}
\hline $\begin{array}{l}\text { Baseline iPTH } \\
\text { group, pg/ml }\end{array}$ & iPTH change, pg/ml & $\mathrm{n}$ & $\begin{array}{l}\text { Event } \\
\text { rate* }\end{array}$ & HR (95\% CI) & $\mathrm{p}$ value & HR (95\% CI) & $\mathrm{p}$ value & HR $(95 \%$ CI $)$ & $\mathrm{p}$ value \\
\hline \multirow[t]{3}{*}{$<150$} & Decreased $(<-50)$ & 1,419 & 290 & $1.68(1.54-1.85)$ & $<0.0001$ & $1.52(1.39-1.67)$ & $<0.0001$ & $1.16(1.06-1.28)$ & 0.0019 \\
\hline & Unchanged $( \pm 50)$ & 8,434 & 238 & $1.38(1.31-1.45)$ & $<0.0001$ & $1.27(1.20-1.33)$ & $<0.0001$ & $1.06(1.00-1.11)$ & 0.0375 \\
\hline & Increased $(>50)$ & 5,428 & 184 & $1.06(1.00-1.13)$ & 0.053 & $1.05(0.99-1.12)$ & 0.1109 & $1.02(0.96-1.08)$ & 0.5653 \\
\hline \multirow{2}{*}{$150-<300$} & Unchanged $( \pm 50)$ & 12,468 & 173 & Ref. & Ref. & Ref. & Ref. & Ref. & Ref. \\
\hline & Increased $(>50)$ & 8,986 & 161 & $0.93(0.88-0.98)$ & 0.0077 & $1.01(0.95-1.06)$ & 0.8418 & $1.07(1.02-1.13)$ & 0.0129 \\
\hline \multirow[t]{3}{*}{$300-<600$} & Decreased $(<-50)$ & 26,788 & 142 & $0.82(0.79-0.86)$ & $<0.0001$ & $0.92(0.88-0.96)$ & $<0.0001$ & $0.98(0.93-1.03)$ & 0.3784 \\
\hline & Unchanged $( \pm 50)$ & 6,261 & 137 & $0.79(0.74-0.84)$ & $<0.0001$ & $0.94(0.88-1.00)$ & 0.0414 & $1.03(0.97-1.10)$ & 0.3578 \\
\hline & Increased $(>50)$ & 5,115 & 145 & $0.84(0.78-0.90)$ & $<0.0001$ & $1.06(0.99-1.14)$ & 0.1099 & $1.15(1.07-1.24)$ & 0.0003 \\
\hline
\end{tabular}

* Per 1,000 patient-years.

Fig. 3. Association of change in serum $\mathrm{Ca}_{\mathrm{Alb}}$ and all-cause mortality across strata of baseline concentration (case-mix and MICS-adjusted).

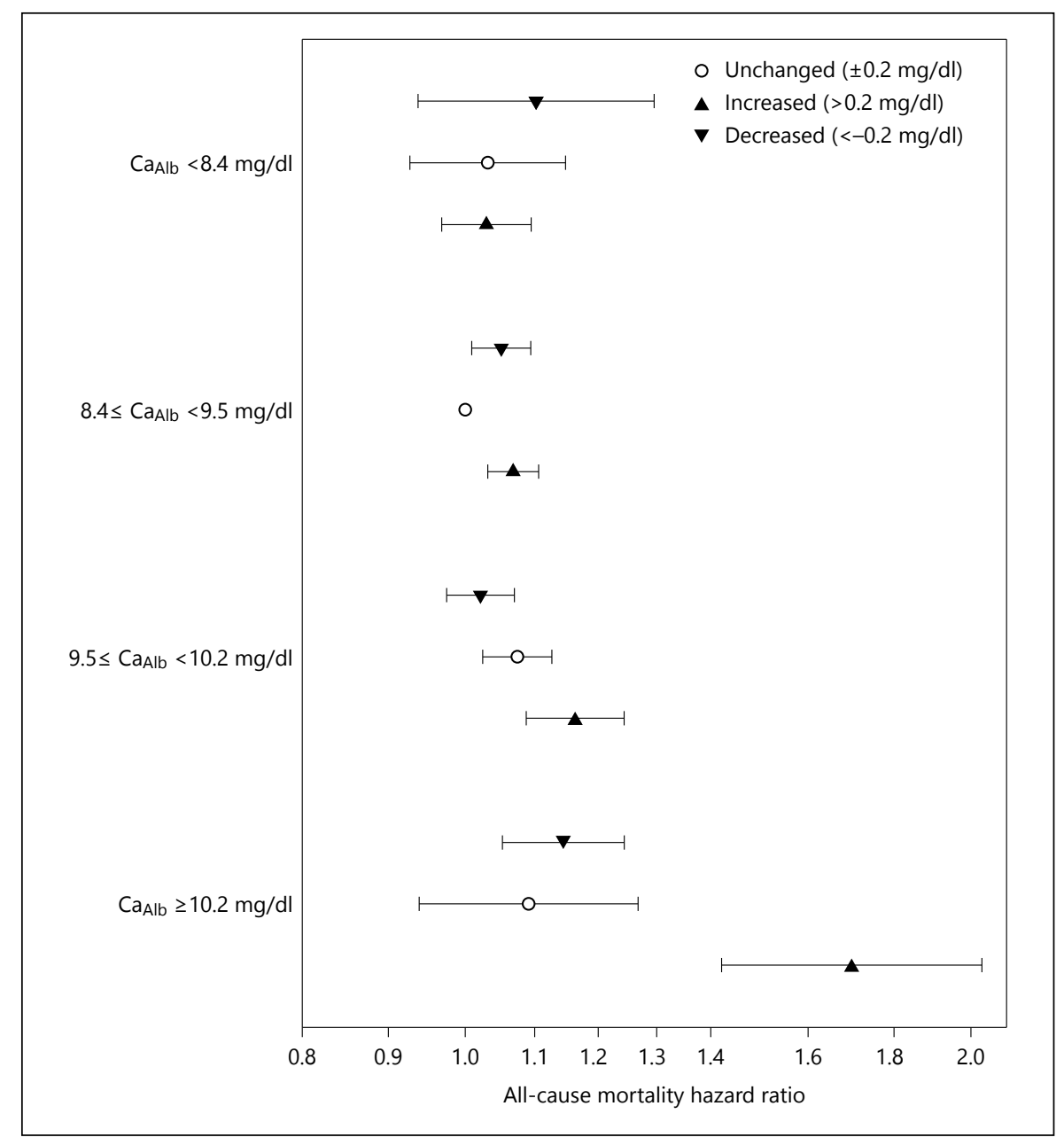


Fig. 4. Association of change in serum iPTH and all-cause mortality across strata of baseline concentration (case-mix and MICS-adjusted).

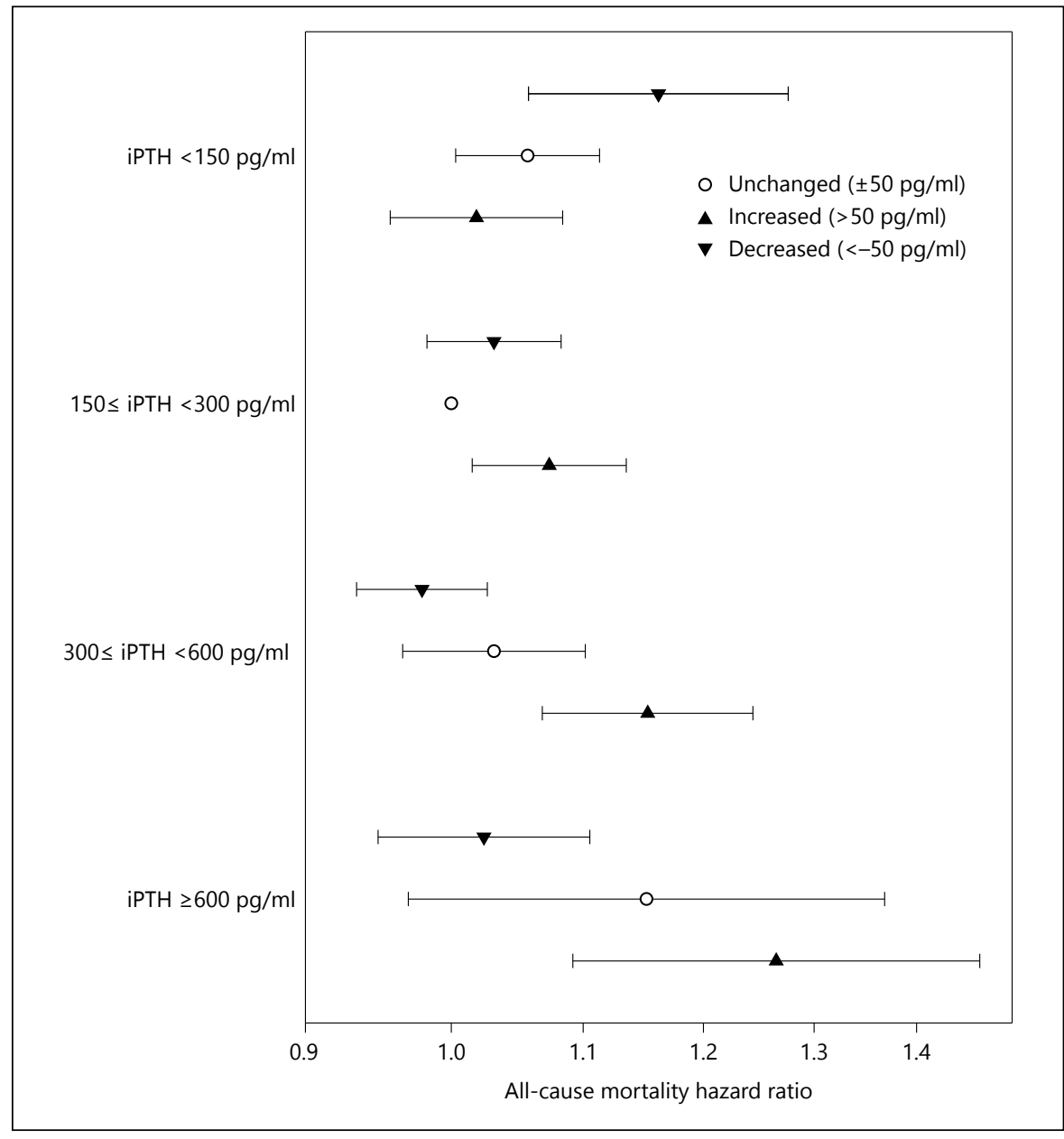

els of iPTH had increased over time from baseline iPTH $\geq 600 \mathrm{pg} / \mathrm{ml}$ experienced the highest risk of mortality (aHR 1.26, 95\% CI 1.09-1.47). Among patients whose iPTH concentrations had decreased in the subsequent quarter, only patients whose baseline iPTH was $<150 \mathrm{pg} /$ $\mathrm{ml}$ experienced a higher risk of mortality (aHR 1.16, 95\% CI 1.06-1.28; fig. 4). In sensitivity analysis, patients whose iPTH levels increased from baseline iPTH of $150-<300$ and $300-<600 \mathrm{pg} / \mathrm{ml}$ were also at a higher risk of mortality. However patients with a baseline iPTH of $300-<600$ $\mathrm{pg} / \mathrm{ml}$ were at a modest but significantly lower risk of mortality when iPTH decreased in the next quarter in comparison to patients who did not experience a change (online suppl. fig. 3).

Change in Serum ALP Level and All-Cause Mortality

Median (IQR) baseline serum ALP concentrations were 87 (69-114) U/l. Patients with high baseline ALP concentrations were more likely to be younger, female, diabetic, and have history of other cardiovascular disease (online suppl. table 4).

Table 5 shows the all-cause mortality HRs for 3 levels of change from baseline to the next quarter across 4 groups of baseline serum ALP concentrations (reference: baseline serum ALP $80-<120 \mathrm{U} / \mathrm{l}$ and unchanged from Q1 to Q2).

In fully adjusted models, patients with a baseline ALP $\geq 80 \mathrm{U} / \mathrm{l}$ and who had an increase in ALP in the subsequent quarter had a significantly higher risk of mortality compared to the reference group. In addition, a decrease in ALP was associated with a higher risk of mortality in patients with a baseline ALP $\geq 120 \mathrm{U} / \mathrm{l}$. In contrast, lower baseline ALP concentrations showed a trend toward lower mortality risk irrespective of the direction of change in ALP level in the subsequent quarter (fig. 5). In sensitivity analysis, an increase in ALP was associated with higher mortality risk compared to no change across all baseline ALP strata (online suppl. fig. 4). 
Fig. 5. Association of change in serum ALP and all-cause mortality across strata of baseline concentration (case-mix and MICS-adjusted).

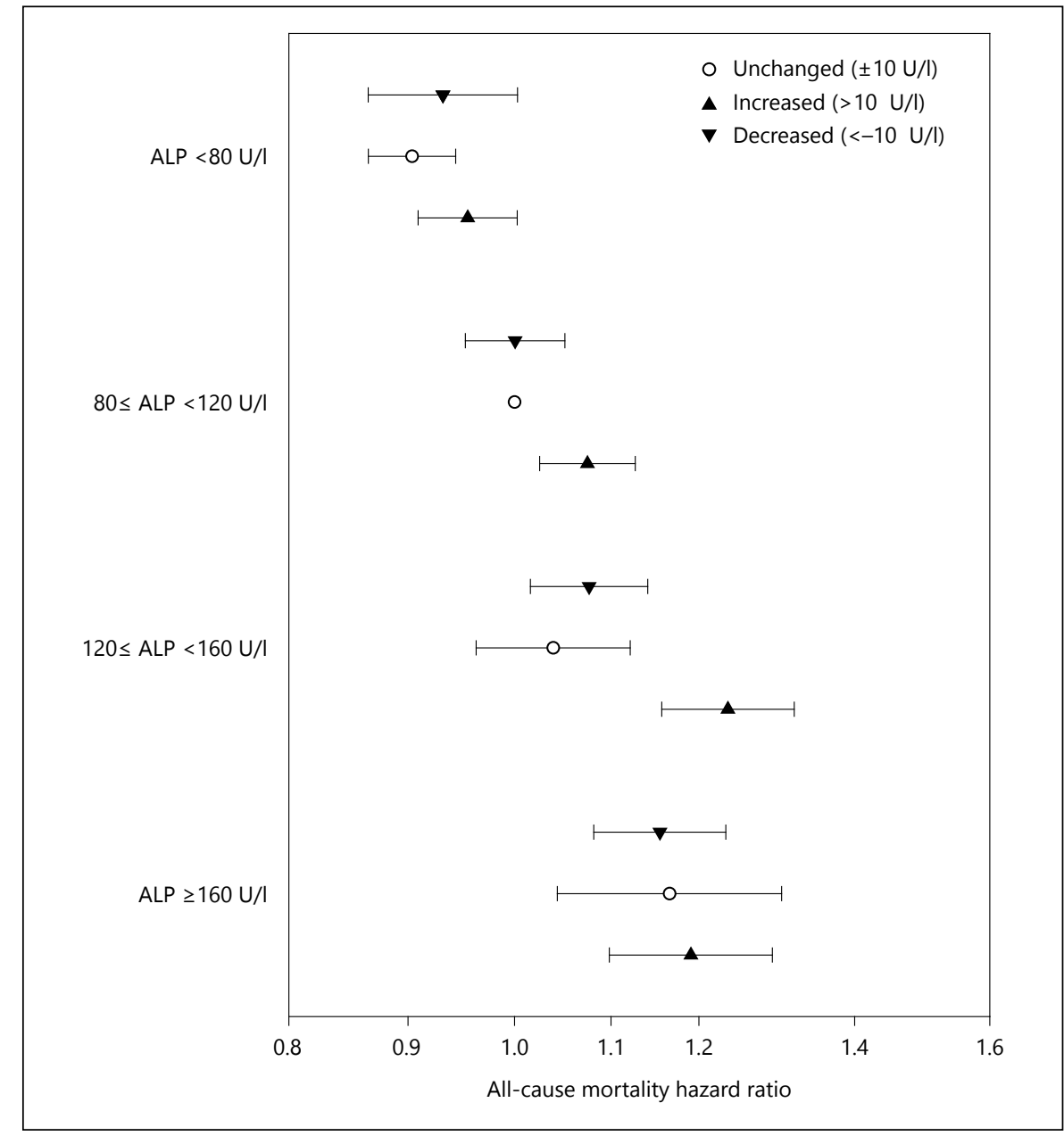

Table 5. All-cause mortality HRs in baseline serum ALP groups and their changes in 102,754 incident HD patients

\begin{tabular}{|c|c|c|c|c|c|c|c|c|c|}
\hline $\begin{array}{l}\text { Baseline ALP } \\
\text { group, U/l }\end{array}$ & ALP change, $U / 1$ & $\mathrm{n}$ & $\begin{array}{l}\text { Event } \\
\text { rate* }\end{array}$ & \multicolumn{2}{|l|}{ Unadjusted } & \multicolumn{2}{|l|}{ Case-mix adjusted } & \multicolumn{2}{|c|}{ Case-mix and MICS-adjusted } \\
\hline \multirow{2}{*}{$<80$} & Unchanged $( \pm 10)$ & 24,590 & 130 & $0.83(0.80-0.87)$ & $<0.0001$ & $0.80(0.77-0.84)$ & $<0.0001$ & $0.90(0.87-0.94)$ & $<0.0001$ \\
\hline & Increased $(>10)$ & 12,448 & 168 & $1.08(1.03-1.13)$ & 0.0027 & $1.01(0.96-1.06)$ & 0.778 & $0.95(0.91-1.00)$ & 0.0631 \\
\hline \multirow[t]{2}{*}{$80-<120$} & Decreased $(<-10)$ & 12,308 & 134 & $0.86(0.82-0.90)$ & $<0.0001$ & $0.93(0.88-0.97)$ & 0.0021 & $1.00(0.95-1.05)$ & 0.9847 \\
\hline & Increased $(>10)$ & 11,194 & 195 & $1.26(1.20-1.32)$ & $<0.0001$ & $1.24(1.18-1.30)$ & $<0.0001$ & $1.07(1.03-1.13)$ & 0.003 \\
\hline \multirow[t]{3}{*}{$120-<160$} & Decreased $(<-10)$ & 6,297 & 158 & $1.02(0.96-1.08)$ & 0.5589 & $1.12(1.06-1.19)$ & $<0.0001$ & $1.08(1.02-1.14)$ & 0.0131 \\
\hline & Unchanged $( \pm 10)$ & 2,706 & 178 & $1.15(1.07-1.24)$ & 0.0003 & $1.21(1.12-1.31)$ & $<0.0001$ & $1.04(0.96-1.12)$ & 0.3236 \\
\hline & Increased $(>10)$ & 3,481 & 246 & $1.58(1.49-1.69)$ & $<0.0001$ & $1.66(1.56-1.77)$ & $<0.0001$ & $1.24(1.16-1.32)$ & $<0.0001$ \\
\hline$\geq 160$ & Decreased $(<-10)$ & 6,009 & 209 & $1.34(1.27-1.42)$ & $<0.0001$ & $1.54(1.46-1.62)$ & $<0.0001$ & $1.15(1.08-1.23)$ & $<0.0001$ \\
\hline
\end{tabular}

* Per 1,000 patient-years. 


\section{Discussion}

We evaluated the association of the change in concentration of 4 MBD markers, Phos, $\mathrm{Ca}_{\mathrm{Alb}}$, iPTH and ALP, during the first 6 months of maintenance HD with allcause mortality in a cohort of 102,754 incident HD patients across strata of baseline MBD markers.

Changes deviating from KDOQI-recommended concentrations (Phos 3.5-<5.5 mg/dl, Ca $\mathrm{Alb}_{\mathrm{Alb}} 8.4-<9.5 \mathrm{mg} / \mathrm{dl}$ and $\mathrm{iPTH} 150-<300 \mathrm{pg} / \mathrm{ml}$ ) were generally associated with higher mortality after adjustment for case-mix and MICS covariates [19]. In addition, both higher baseline and increased ALP $\geq 80 \mathrm{U} / \mathrm{l}$ concentrations showed a trend towards higher risk of mortality. These findings provide additional evidence for more precise management of CKD-MBD markers during the first 6 months of treatment.

Previous observational studies have highlighted the importance of adherence to the KDOQI-recommended levels of serum Phos, calcium and iPTH from the beginning of HD treatment, demonstrating additive effects gained by the achievement of the recommended target levels on patient survival $[20,21]$. In addition, one study found that patients who achieved recommended ranges for a shorter duration of time had a higher risk of death [20]. Our results were conceptually in line with these studies. Moreover, this study provided further insight about mortality risk related to changes in serum CKD-MBD markers when stratified by their baseline levels.

An increased risk in mortality in the fully adjusted model was found in patients who deviated from baseline $\mathrm{Ca}_{\mathrm{Alb}} 8.4-<9.5 \mathrm{mg} / \mathrm{dl}$, as well as among patients who maintained a stable concentration of baseline $\mathrm{Ca}_{\mathrm{Alb}}$ 9.5$<10.2 \mathrm{mg} / \mathrm{dl}$. While these results provide support for the KDOQI guideline to maintain a lower normal range of $\mathrm{Ca}_{\mathrm{Alb}} 8.4-<9.5 \mathrm{mg} / \mathrm{dl}$, this opposes the KDIGO guidelines with its recommendations of normal $\mathrm{Ca}_{\mathrm{Alb}}$ range as 8.6$10.2 \mathrm{mg} / \mathrm{dl}$. It should be noted that this study population was composed of incident HD patients, and thus the optimal range may differ from maintenance $\operatorname{HD}[4,11]$. This is also the case for iPTH where the recommended normal range is $160-720 \mathrm{pg} / \mathrm{ml}$. Among patients who experienced an increase in iPTH, baseline iPTH levels $\geq 150$ $\mathrm{pg} / \mathrm{ml}$ were incrementally associated with higher mortality. In addition, patients with lower iPTH concentrations at baseline and who experienced a further decrease in the subsequent quarter also exhibited a higher risk of mortality, which is consistent with previous reports and the KDOQI guidelines $[4-9,11,12,19]$.
Among the CKD-MBD parameters examined in this study, deviations in serum Phos concentrations at both extremes were associated with higher all-cause mortality. Higher concentrations as well as excessive changes from the recommended range $(3.5-<5.5 \mathrm{mg} / \mathrm{dl})$ were associated with higher mortality, and the risk was dependent on the differences in concentration from that range. Meanwhile, an increase in serum ALP concentration was associated with higher mortality risk across baseline strata of ALP $\geq 80 \mathrm{U} / 1$. These results support the importance and robustness of serum ALP concentration as an MBD biomarker that predicts mortality $[4-9,11,12,19,22]$. Although associations between low ALP and mortality were not significant in our analyses, a previous study investigating the effect of change in ALP on mortality showed similar results. These findings suggest that the relationship of decreased ALP and mortality may be impacted by baseline ALP concentrations [6].

Several factors might have contributed to these findings and there are a number of limitations to this study. First, pre-dialysis care and patient condition may affect survival more potently than treatments administered after dialysis initiation in incident HD patients who bear the highest mortality risk $[4,6,23]$. Although we did adjust for the use of intravenously delivered vitamin $D$ medications, data on other prescription, behavior and dietary interventions were not available in this study. We cannot analyze the impact of interventions such as phosphate binders, oral active or nutritional vitamin D dose, or surgical interventions such as parathyroidectomy on the associations between CKD-MBD markers and mortality. We also acknowledge that another limitation in this study is the inability to address other CKD-MBDrelated factors in the blood such as fibroblast growth factor- 23 or vitamin D metabolites. Despite rigorously adjusting for markers of malnutrition and inflammation, other variables namely C-reactive protein and dialysate calcium were unavailable in this cohort, and we cannot exclude residual confounding given the observational study design. Furthermore, we only evaluated changes during the first 6 months of dialysis treatment but not in the subsequent periods to focus on the immediate changes after dialysis initiation in CKD-MBD markers. Future studies are needed to investigate whether these associations differ according to dialysis vintage. Finally, cause of death was unavailable in our cohort.

Strengths of our study include a large nationally representative incident HD population with detailed patient level data, which allowed us to rigorously account
Soohoo et al. 
for a range of clinically relevant factors. Essentially all incident HD patients in the original cohort were included in our analyses, and thus the likelihood of selection bias is minimized. Additionally, all dialysis facilities were under uniform administrative care, and all laboratory tests were performed in one single laboratory with optimal quality assurance monitoring. We used quarterly averaged measurements rather than one single baseline measurement at to minimize effects of shortterm variations. Furthermore, the relationship of CKDMBD and mortality is multi-faceted and involves multiple MBD markers. In our fully adjusted models, we adjusted for the other MBD markers and their change aside from the exposure of interest, suggesting that our findings are independent of other MBD markers change and baseline measurements.

\section{Conclusion}

In conclusion, we demonstrated that baseline levels and changes in serum concentrations of CKD-MBD-related parameters in the first 6 months after initiation of HD treatment were differentially associated with allcause mortality in patients with ESRD. Further studies are needed to evaluate whether stricter interventions to correct these abnormalities in the early period after HD initiation can improve patient survival.

\section{Author Contributions}

Study design: M.S., M.F., Y.O., E.S., C.M.R., C.P.K. and K.K.-Z. Study conduct: M.S., M.F., Y.O., E.S. and K.K.-Z. Data analysis: M.S., M.F. and E.S. Data interpretation: M.S., M.F., Y.O., E.S.,
C.M.R., W.L.L., J.W., V.A.R., S.B., C.P.K. and K.K.-Z. Drafting of the manuscript: M.S., M.F., Y.O., E.S., C.M.R., W.L.L., J.W., V.A.R., S.B., C.P.K. and K.K.-Z. Revising manuscript content: M.S., Y.O., E.S. and K.K.-Z. Approving final version of manuscript: M.S., M.F., Y.O., E.S., C.M.R., W.L.L., J.W., V.A.R., S.B., C.P.K. and K.K.-Z. Each author contributed important intellectual content during manuscript drafting and accepts accountability for the overall work by ensuring that questions pertaining to the accuracy or integrity of any portion of the work are appropriately investigated and resolved. K.K.-Z. takes responsibility for the integrity of the data analysis.

\section{Funding Source}

The work in this manuscript has been performed with the support of the National Institute of Diabetes, Digestive and Kidney Disease of the National Institute of Health research grants R01-DK95668 (K.K.-Z.), K24-DK091419 (K.K.-Z.), R01DK078106 (K.K.-Z.). K.K.-Z. is supported by philanthropic grants from Mr. Harold Simmons, Mr. Louis Chang, Dr. Joseph Lee and AVEO. C.P.K. is supported by the National Institute of Diabetes, Digestive and Kidney Disease grants R01-DK096920 and U01-DK102163. Y.O. has been supported by the Shinya Foundation for International Exchange of Osaka University Graduate School of Medicine Grant. C.M.R. is supported by the National Institute of Diabetes, Digestive and Kidney Disease grant K23-DK102903.

\section{Disclosure Statement}

K.K.-Z. has received honoraria and/or support from Abbott, Abbvie, Alexion, Amgen, American Society of Nephrology, AstraZeneca, AVEO, Chugai, DaVita, Fresenius, Genetech, Haymarket Media, Hospira, Kabi, Keryx, National Institutes of Health, National Kidney Foundation, Relypsa, Resverlogix, Sanofi, Shire, Vifor, ZS-Pharma. C.P.K. has received honoraria from Sanofi-Aventis, Relypsa and ZS Pharma.

\section{References}

1 Stevens LA, Djurdjev O, Cardew S, Cameron EC, Levin A: Calcium, phosphate, and parathyroid hormone levels in combination and as a function of dialysis duration predict mortality: evidence for the complexity of the association between mineral metabolism and outcomes. J Am Soc Nephrol 2004;15:770-779.

2 Block GA, Klassen PS, Lazarus JM, Ofsthun $\mathrm{N}$, Lowrie EG, Chertow GM: Mineral metabolism, mortality, and morbidity in maintenance hemodialysis. J Am Soc Nephrol 2004; 15:2208-2218.

3 Young EW, Albert JM, Satayathum S, Goodkin DA, Pisoni RL, Akiba T, Akizawa T, Kurokawa K, Bommer J, Piera L, Port FK: Predictors and consequences of altered mineral metabolism: the dialysis outcomes and practice patterns study. Kidney Int 2005;67:1179-1187.

4 Kalantar-Zadeh K, Kuwae N, Regidor DL, Kovesdy CP, Kilpatrick RD, Shinaberger CS, McAllister CJ, Budoff MJ, Salusky IB, Kopple JD: Survival predictability of time-varying indicators of bone disease in maintenance hemodialysis patients. Kidney Int 2006;70:771-780.

5 Tentori F, Blayney MJ, Albert JM, Gillespie BW, Kerr PG, Bommer J, Young EW, Akizawa T, Akiba T, Pisoni RL, Robinson BM, Port FK: Mortality risk for dialysis patients with different levels of serum calcium, phosphorus, and PTH: the dialysis outcomes and prac- tice patterns study (DOPPS). Am J Kidney Dis 2008;52:519-530.

6 Regidor DL, Kovesdy CP, Mehrotra R, Rambod M, Jing J, McAllister CJ, Van Wyck D, Kopple JD, Kalantar-Zadeh K: Serum alkaline phosphatase predicts mortality among maintenance hemodialysis patients. J Am Soc Nephrol 2008;19:2193-2203.

7 Kalantar-Zadeh K, Miller JE, Kovesdy CP, Mehrotra R, Lukowsky LR, Streja E, Ricks J, Jing J, Nissenson AR, Greenland S, Norris KC: Impact of race on hyperparathyroidism, mineral disarrays, administered vitamin $\mathrm{D}$ mimetic, and survival in hemodialysis patients. J Bone Miner Res 2010;25:2724-2734. 
8 Rivara MB, Ravel V, Kalantar-Zadeh K, Streja E, Lau WL, Nissenson AR, Kestenbaum B, de Boer IH, Himmelfarb J, Mehrotra R: Uncorrected and albumin-corrected calcium, phosphorus, and mortality in patients undergoing maintenance dialysis. J Am Soc Nephrol 2015; 26:1671-1681.

9 Streja E, Wang HY, Lau WL, Molnar MZ, Kovesdy CP, Kalantar-Zadeh K, Park J: Mortality of combined serum phosphorus and parathyroid hormone concentrations and their changes over time in hemodialysis patients. Bone 2014;61:201-207.

10 Isakova T, Wahl P, Vargas GS, Gutiérrez OM, Scialla J, Xie H, Appleby D, Nessel L, Bellovich K, Chen J, Hamm L, Gadegbeku C, Horwitz E, Townsend RR, Anderson CA, Lash JP, Hsu CY, Leonard MB, Wolf M: Fibroblast growth factor 23 is elevated before parathyroid hormone and phosphate in chronic kidney disease. Kidney Int 2011;79:1370-1378.

11 KDIGO clinical practice guideline for the diagnosis, evaluation, prevention, and treatment of chronic kidney disease-mineral and bone disorder (CKD-MBD). Kidney Int Suppl 2009;113:S1-S130.

12 Steddon S, Sharples E: Renal association clinical practice guideline in mineral and bone disorders in CKD. Nephron Clin Pract 2011; 118(suppl 1):c145-c152.
13 Fukagawa M, Yokoyama K, Koiwa F, Taniguchi M, Shoji T, Kazama JJ, Komaba H, Ando R, Kakuta T, Fujii H, Nakayama M, Shibagaki Y, Fukumoto S, Fujii N, Hattori M, Ashida A, Iseki K, Shigematsu T, Tsukamoto Y, Tsubakihara Y, Tomo T, Hirakata H, Akizawa T: Clinical practice guideline for the management of chronic kidney disease-mineral and bone disorder. Ther Apher Dial 2013;17:247-288.

14 Robinson BM, Zhang J, Morgenstern $\mathrm{H}$, Bradbury BD, Ng LJ, McCullough KP, Gillespie BW, Hakim R, Rayner H, Fort J, Akizawa T, Tentori F, Pisoni RL: Worldwide, mortality risk is high soon after initiation of hemodialysis. Kidney Int 2014;85:158-165.

15 Lukowsky LR, Kheifets L, Arah OA, Nissenson AR, Kalantar-Zadeh K: Patterns and predictors of early mortality in incident hemodialysis patients: new insights. Am J Nephrol 2012;35:548-558.

16 Kuttykrishnan S, Kalantar-Zadeh K, Arah OA, Cheung AK, Brunelli S, Heagerty PJ, Katz R, Molnar MZ, Nissenson A, Ravel V, Streja E, Himmelfarb J, Mehrotra R: Predictors of treatment with dialysis modalities in observational studies for comparative effectiveness research. Nephrol Dial Transplant 2015;30: 1208-1217.

$17 \mathrm{~K} / \mathrm{DOQI}$ clinical practice guidelines for bone metabolism and disease in chronic kidney disease. Am J Kidney Dis 2003;42:S1-S201.

18 Lukowsky LR, Molnar MZ, Zaritsky JJ, Sim JJ, Mucsi I, Kovesdy CP, Kalantar-Zadeh K: Mineral and bone disorders and survival in hemodialysis patients with and without polycystic kidney disease. Nephrol Dial Transplant 2012;27:2899-2907.
19 Belozeroff V, Goodman WG, Ren L, Kalantar-Zadeh K: Cinacalcet lowers serum alkaline phosphatase in maintenance hemodialysis patients. Clin J Am Soc Nephrol 2009;4: 673-679.

20 Danese MD, Belozeroff V, Smirnakis K, Rothman KJ: Consistent control of mineral and bone disorder in incident hemodialysis patients. Clin J Am Soc Nephrol 2008;3:14231429.

21 Cozzolino M, Messa P, Brancaccio D, Cannella G, Bolasco P, Di Luca M, Costanzo AM, Paparatti Ud, Festa V, Gualberti G, Mazzaferro S: Achievement of NKF/K-DOQI recommended target values for bone and mineral metabolism in incident hemodialysis patients: results of the FARO-2 cohort. Blood Purif 2014;38:37-45.

22 Lau WL, Kalantar-Zadeh K, Kovesdy CP, Mehrotra R: Alkaline phosphatase: better than PTH as a marker of cardiovascular and bone disease? Hemodial Int 2014;18:720724.

23 Melamed ML, Eustace JA, Plantinga L, Jaar BG, Fink NE, Coresh J, Klag MJ, Powe NR: Changes in serum calcium, phosphate, and PTH and the risk of death in incident dialysis patients: a longitudinal study. Kidney Int 2006; 70:351-357. 